\title{
FILOSOFIA PARA CRIANÇAS: \\ APONTAMENTOS REFLEXIVOS
}

\author{
Alvino Moser* \\ Daniel Soczek**:
}

\begin{abstract}
RESUMO
O objetivo deste artigo é apresentar algumas considerações sobre o ensino, numa perspectiva filosófica, para crianças. Partimos do pressuposto que o filosofar é uma atividade própria do ser humano, mas poucos são os alunos de ensino médio e superior que iniciam as aulas de Filosofia nela interessados. Nossa hipótese é de que a postura filosófica da criança lhe é subtraída ou subjugada por processos educacionais formais ou informais que, numa perspectiva instrumental, limitam a condição humana a uma cultura de massas, na perspectiva de uma indústria cultural que assume novas dimensões pelo desenvolvimento das Tecnologias de Informação e Comunicação (TICs). Na tentativa de apresentar algumas reflexões críticas sobre o processo de formação da criança, o percurso deste texto é, num primeiro momento, fazer uma breve explanação sobre alguns significados do que é ser criança no mundo contemporâneo. No segundo momento, defenderemos a ideia de que a predisposição ao filosofar é uma capacidade que aparece nos anos iniciais da existência humana para, num terceiro momento, discutir como aproveitar esta predisposição para a reflexão filosófica como elemento fundante do processo educacional.
\end{abstract}

Palavras-chave: Filosofia. Ensino de Filosofia. Filosofia para crianças.

\begin{abstract}
PHILOSOFY FOR CHILDREN: A BRIEF REFLECTION

This paper aims to present some reflection on teaching philosophy to children. We believe philosophizing is a human activity, but there are only a few High School and college students interested in it. Our hypothesis is that the formal and informal educational processes discourage children in their dispositions toward philosophy. That occurs because our contemporary society promotes the "mass culture" which limits human condition. This perspective acquires new dimensions with the advent and development of Information and Communication Technologies (ICTs). In order to
\end{abstract}

\footnotetext{
* Doutor em Ética pela Université Catholique de Louvain, Bélgica. Professor do Centro Universitário UNINTER. Pesquisador do Núcleo de Pesquisas em Educação da UNINTER. Endereço para correspondência: UNINTER - Rua Saldanha Marinho, 131 - Centro, Curitiba-PR. CEP: 80410-150. moseral.am@gmail,com

** Doutor em Sociologia Política pela Universidade Federal de Santa Catarina (UFSC). Professor do Centro Universitário UNINTER e da Secretaria do Estado de Educação do Estado do Paraná (SEED-PR). Pesquisador do Núcleo de Pesquisas em Educação da UNINTER. Endereço para correspondência: Rua José Rodrigues Pinheiro, 565, Capão-Raso, Curitiba- PR. CEP: 81130-200.danielsoczek@terra.com.br; daniel.s@grupouninter.com.br
} 
present some critical reflection on child's education process, we follow three steps: first, a brief explanation of what means to be a child in the contemporary world. Second, we present the thesis that in their first years of life children are endowed with the capacity for philosophizing. Finally, we discuss how we can take this child's predisposition to philosophy as a fundamental source of the educational process.

Keywords: Philosophy. Teaching Philosophy. Philosophy for Children

\section{Introdução}

Dentre as muitas problematizações construídas e reconstruídas no âmbito filosófico, uma das mais interessantes do nosso ponto de vista, atualmente, refere-se à fundamentação epistemológica quanto ao que seria importante, considerando as condições materiais de existência contemporâneas, para embasar e/ou consolidar o que chamamos de pensamento filosófico. Dentre os possíveis desdobramentos dessa problemática destacamos, dentre outras, duas questões: como e por que ensinar/ aprender o filosofar.

Quanto à pergunta "por que ensinar/aprender filosofia?", existe um posicionamento "consensuado" no Brasil quanto à sua importância para compreensão e (re)construção da realidade, ainda que constituído por diversos vieses e perspectivas. Basta, nesse sentido, ler a introdução ou algum capítulo específico da maioria dos livros ou manuais de ensino de Filosofia. Contudo, quanto ao "como se aprende filosofia", o foco da questão requer o olhar atento do professor que, em sala, é demandado a desenvolver processos dialógicos de construção da realidade com os estudantes, gerando, necessariamente, conflitos derivados do contraste entre posturas ideológicas diversas.

Em uma sala de aula, seja do ensino médio ou da graduação (em cursos que não o de Filosofia), temos uma realidade quali-quantitativa desafiadora: alguns poucos estudantes vêm até a sala de aula interessados no estudo da Filosofia. Em sua grande maioria, esses estudantes trazem consigo preconceitos recorrentes quanto aos conteúdos e abordagem da Filosofia em sala de aula. Esses preconceitos podem ser percebidos nos comentários entre os estudantes no que diz respeito à Filosofia: é comum associar a imagem do professor de filosofia como um "louco" ou ateu, por exemplo. Em muitas situações, esses e outros preconceitos limitam a discussão filosófica, desviando o campo da reflexão para o campo dos dogmatismos e falácias. Eventos na sala de aula derivados dessas concepções equivocadas muitas vezes deixam implícito, e outras claramente explicitado, que o estudante, pelo menos nas primeiras aulas, não pretende fazer parte dos processos de ensino e aprendizagem de Filosofia. Sua permanência física na sala de aula decorre muitas vezes da coerção exercida pelo currículo numa perspectiva burocrática: se não fizer a disciplina, reprova! Dificuldades dessa natureza deixam os professores apreensivos. Frente a esse quadro, o professor de Filosofia é desafiado a estimular os estudantes a aceitar o convite à Filosofia, parafraseando o livro de Chauí (2004).

Dentre as possíveis respostas ao desafio acima apontado, uma das possibilidades de abordagem dessa questão está relacionada ao seguinte questionamento: a partir de que momento e sob quais circunstâncias, efetivamente, o ser humano estaria em condições de pensar sobre si mesmo e seu mundo? Em que momento e como essa disposição é negada ou, ao menos, não cultivada nos processos de ensino? Se o estudante chega ao ensino médio e superior com os preconceitos e posturas acima mencionadas, tais condições e atitudes merecem ser pensadas também na perspectiva dos processos escolares aos quais as crianças foram anteriormente submetidas. Nesse sentido, duas questões principais norteiam nossa reflexão. A primeira, como (re)pensar a prática de formação das crianças para o exercício do pensamento filosófico? Segunda, como essa experiência de significação e ressignificação da realidade pelo pensamento filosófico pode ser resgatada no estudante em processo de formação mais adiantado (ensino médio e ensino superior)?

Partimos do pressuposto, adiante explicitado, de que o filosofar é uma atividade própria do ser 
humano, fundamental para o desenvolvimento individual e coletivo dos sujeitos sociais. Nossa hipótese é que a postura filosófica da criança lhe é subtraída ou subjugada por processos educacionais formais ou informais que, numa perspectiva instrumental, limitam a condição humana a uma cultura de massas, continuamente reafirmada pelas Tecnologias de Informação e Comunicação (TICs). Este texto abordará, em grande parte, a primeira questão com o objetivo de, a partir dessas reflexões, lançar alguma luz sobre a segunda questão.

As discussões sobre os processos de ensino/ aprendizagem de Filosofia para o público infantil e infanto-juvenil têm muitas perspectivas e estão em desenvolvimento em muitas frentes como cursos de extensão e especialização, eventos regionais, nacionais e internacionais ligados a esta temática, bem como produção de dissertações e teses ${ }^{1}$, além de artigos de revistas científicas ${ }^{2}$ e, é claro, de pesquisas realizadas em ferramentas de consulta da internet como o Google. Ainda temos editoras especializadas em obras de filosofia ${ }^{3}$ e a publicação de outros materiais como jornais disponibilizados em blogs ${ }^{4}$. Considerando a diversidade de propostas e projetos quanto ao ensino de filosofia para crianças, damos algum destaque às reflexões aqui desenvolvidas para a proposta elaborada e implantada por Lipman e seus colaboradores (LELEUX, 2008) na Universidade de Columbia, sem desconsiderar as críticas a ela direcionadas. Essa proposta tem origem entre os anos 60-70 do milênio passado e foi discutida, (re)pensada e melhorada nas décadas seguintes, sendo hoje trabalhada em diversos países.

Para trabalhar as questões acima pontuadas, este texto se divide em momentos articulados entre si. Num primeiro momento será realizada uma breve explanação sobre o que significa ser

1 Estas dissertações ou teses podem ser acessadas pela consulta ao banco de teses da Capes, disponível em: $<\mathrm{http}: / /$ capesdw.capes.gov. $\mathrm{br} /$ capesdw/>.

2 Muitos desses artigos, avaliados criteriosamente e disponibilizados em revistas, podem ser acessados em bases de periódicos como o Scielo, pelo site $<$ http://www.scielo.org.br $>$.

3 Destacamos aqui duas delas: a Vozes, $<$ http://www.universovozes. com.br/> e a Shofos, <http://www.editorasophos.com.br/>, cujos catálogos estão disponíveis on-line nos referidos sites.

4 Existem centenas, talvez milhares de blogs sobre filosofia e seu ensino. Dentre eles destaco o "Corujinha", que surgiu de uma tradição de 23 anos de publicações em Filosofia, disponível em $<$ http://jornalcorujinha.blogspot.com.br/>. criança no mundo contemporâneo. Em seguida, será defendida a ideia de que a predisposição ao filosofar é uma capacidade humana que aparece nos anos iniciais da existência para, num terceiro momento, discutir como aproveitar esta predisposição para pensar ensino de filosofia para crianças e jovens. Este texto conta, em alguns momentos, com certa licença poética e está pautado pela nossa experiência como professores, refletindo, portanto, nossa concepção de ensino. Não afirmamos que as opções teóricas aqui tomadas sejam as melhores nem as piores linhas de análises e nem propomos alguma sistematização quanto ao estado atual da arte referente ao debate dessa temática. Apresentamos, tão somente, pontos de vista que nos parecem convenientes no intuito de suscitar debates sobre o ensino de filosofia para crianças e pensar como este movimento pode ser aproveitado para qualificar a formação dos estudantes ao longo de todo o seu processo formativo e para além dele.

\section{O surgimento da concepção con- temporânea de criança como "nativas digitais"}

As globalizações e os processos de mundialização (HARVEY, 1993; IANNI, 1996; SANTOS, M., 2000; SADER, 2004), o grande acúmulo e disponibilização de informações pelo acelerado desenvolvimento das tecnologias (CASTELLS, 2003), a crítica aos seus usos (JONAS, 2006) são alguns dos elementos que influenciam o processo de desenvolvimento da pessoa e da sociedade. Discutir a condição da criança no mundo contemporâneo e sua presença na Escola (no Brasil, 96,7\% das crianças entre 7 e 14 anos, segundo o IBGE, estão devidamente matriculadas), nesse ambiente pautado pelas TICs, é algo extremamente desafiador, principalmente se propusermos uma reflexão sobre o papel da Escola. Ao deixar uma criança adentrar os muros da Escola, pelo menos duas perguntas incitam nossa reflexão: o que a Escola espera de um estudante em qualquer disciplina e qualquer grau de ensino e o que a sociedade espera desta pessoa em formação. Devemos considerar que, talvez, esses dois conjuntos de expectativas sejam diferentes e, inclusive, divergentes e conflitantes entre si como abordado mais adiante. 
Em termos históricos, no mundo ocidental a representação da ideia de infância como concebemos hoje remonta à França dos séculos XVII e XVIII (ARIÈS, 1978). Até há alguns séculos a criança era considerada apenas um homúnculo, ou seja, um adulto em miniatura. Essa visão de mundo pode ser percebida nas várias representações de crianças desse período histórico usando roupas, tendo posturas e realizando atividades específicas "do mundo adulto". Foi Erasmo de Rotterdam (2008) um dos pioneiros no mundo moderno ocidental a pregar que as crianças não são adultos em miniatura e que, portanto, não deveriam ser tratadas como adultos. As crianças teriam, segundo ele, um modo próprio de ser, diferente do modo dos adultos e que, fundamentalmente, deve ser respeitado. $\mathrm{O}$ movimento histórico de construção e afirmação de uma identidade infantil teve, como todo processo dialético, muitos avanços e retrocessos em razão das mais diversas circunstâncias históricas, e consideramos que o saldo atual desse processo histórico é positivo. No Brasil, por exemplo, existe até uma previsão legal de seguridade dos direitos das crianças estabelecido pelo Estatuto da Criança e do Adolescente, Lei $\mathrm{n}^{\circ} 8.069$, de 13 de julho de 1990 (BRASIL, 1990).

Não obstante todo esforço histórico dos últimos séculos a fim de oferecer às crianças uma visibilidade social diferenciada, respeitando as idiossincrasias de sua condição, temos, em Postman (1999), dentre outros, a tese de um grave retrocesso neste movimento emancipador. Em sua obra $O$ Desaparecimento da Infância, esse autor constata que a condição de ser criança estaria desaparecendo por conta da alienação provocada pela televisão. Isso se deveria ao fato de que, em geral, diante da TV as pessoas ficam passivas e não têm como interagir com a tela, sendo manipuladas por seus enredos. Destaque-se nesse movimento, dentre outros elementos, o forte apelo ao consumismo e às questões referentes a disputas ideológicas implícitas e explícitas.

A utilização massiva da televisão como meio de comunicação e entretenimento apresenta consequências nefastas para a infância, demonstradas, entre outros, por Salgado, Pereira e Jobim e Souza (2005), posto que a manutenção e perpetuação de sua programação estão asseguradas pelo seu potencial econômico, com o qual está comprometida. Como medir, por exemplo, os impactos cognitivos e o que fazer com uma criança que, ao chegar à pré-escola, já esteve exposta a milhares de horas na frente de uma televisão, condição esta que, possivelmente, perdurará durante longos anos? Não podemos deixar de lembrar que crianças, em seu processo de socialização, têm como uma de suas características a imitação dos exemplos de seu entorno social. Como diziam os clássicos, exempla trahunt: os exemplos arrastam. A criança imita o que vê e, assim, podemos observar a veracidade do que afirma Dawkins (2007): não apenas os genes se transmitem, mas também os memes, isto é, certos traços culturais, nem sempre os melhores. Não obstante todas as críticas a esse fenômeno e o uso cada vez maior de outras mídias possibilitadas pela internet, não podemos deixar de lembrar que nunca se ganhou tanto com a propaganda televisa, em razão de sua grande audiência ${ }^{5}$.

Os estímulos, a interação não só com a televisão, mas também com os mais diversos recursos tecnológicos, como os aparelhos celulares e o computador, acabam criando relações síncronas e assíncronas, despertando novas compreensões de mundo, interesses e linguagens ${ }^{6}$. Participando de jogos eletrônicos, interagindo com os também conectados amigos no Orkut, Facebook e outras comunidades virtuais, as crianças constroem novos sentidos para a realidade, gerando discussões muito interessantes sobre a condição humana na perspectiva do "pós-humano" (SANTAELLA, 2003). Do ponto de vista da história da filosofia, ir "além das aparências" ou superar a " $\delta o \xi \alpha$ " (doxa, opinião) era um dos lemas de Sócrates e Platão (PLATÃO, 1994), dentre muitos outros filósofos, preocupação e meta sustentada heroicamente até a modernidade. Entretanto, com a crise da razão moderna, fomos confrontados com a hipótese da inexistência de uma verdade universal e a inviabilidade teórica do

5 Na última novela da Rede Globo, por exemplo, no capítulo final, a inserção de um comercial saiu por R $\$ 500$ mil, e o merchandising variou entre R\$ 1 e 1,8 milhão de reais, segundo reportagem de Almeida (2012).

6 Um levantamento de dados sobre o uso das tecnologias por crianças e jovens encontra-se na pesquisa, publicada em 2012, intitulada Gerações Interativas Brasil: Crianças e Adolescentes Diante da Tela, disponível em <http://fundacaotelefonica.org.br/Uploads/ book_telefonica_2_final.pdf $>$. 
uso de conceitos como "evidência". Pela guinada linguística nos século XX, começamos a ponderar os elementos simbólicos da linguagem, suas representações numa perspectiva cética, relativista, culturalista. Ainda que Parmênides (1973) nos alertasse para que não se fizesse confusão entre o ser e o não ser, temos que admitir: Heráclito venceu, pois “ $\pi \alpha \nu \tau \alpha \rho \varepsilon$ ”, tudo muda.

Fruto dese processo histórico, uma das características das crianças dessa era digital marcada pela liquidez (BAUMAN, 1998, 1999, 2003, 2005) é a fuga do silêncio. $\mathrm{O}$ uso frequente de celulares, iPhones, iPad, iPod e, sobretudo, das redes sociais promove uma condição de ausência do silêncio que consideramos aqui condição fundamental para a reflexão. Como é possível realizar uma reflexão com um livro na mão, na frente da televisão e com algum aparelho de som ligado ao ouvido? Somos "dinossauros" ou "vanguarda" ao propor o silêncio como fundamento educativo dessa "nova era"? A leitura e a escrita, quando realizadas em diferenciadas plataformas de comunicação, seguem padrões de aligeiramento que impedem a reflexão. Basta olhar a forma escrita utilizada para além da gramática escolar nos chats e redes sociais. Vale perguntar quantos estudantes, de qualquer sala de aula, que não compreendendo um conteúdo específico, tomasse por tarefa a releitura do assunto duas, três, quatro vezes até entende-lo, numa perspectiva obstinada pelo conhecimento. Não há espaço e tempo para essa atitude - espaço e tempo possuem, hoje, dimensões diversas. E se a filosofia precisa ensinar a bem pensar, como nos adverte Lipman (1990), é preciso que as pessoas de todas as idades, principalmente as crianças, construam espaços de silêncio e disposição para a retomada cuidadosa e atenta daquilo que lhes escapa ou é dificultoso. Nesse sentido, Tapscott (1997) assinalava a preocupação de psicólogos que previam uma geração superficial, assim como Bauerlein (2008) em The Dumbest Generation: How the Digital Age Stupefies Young Americans and Jeopardizes Our Future (Or, Don't Trust Anyone Under 30).

A origem de parte significativa dos problemas das relações de ensino está relacionada ao fato dos educadores ou docentes não se preocuparem em adquirir conhecimentos sobre o perfil das crianças que já não podem ser enquadradas em modelos/ padrões e expectativas estudadas e pesquisadas há algumas décadas. É preciso levar em consideração as novas dinâmicas sociais que interferem diretamente em todos os processos sociais e, em especial, do nosso ponto de vista, as relações escolares. É uma condição nova - as crianças são "nativas digitais" (PRENSKY, 2001, 2010), expressão que dele tomamos de empréstimo para o título desta seção. Nesse sentido, vale destacar, dentre tantos outros exemplos, o esforço de pesquisadores como Fantin e Rivoletta (2010) no artigo Crianças na Era Digial: Desafios da Comunicação e da Educação, que traz vários relatos de pesquisas feitas em escolas de ensino fundamental com o uso de recursos metodológicos como fotos pelo celular, projeção de DVD e visualização de streamers em sites como o Youtube. As crianças se animam, se interessam e prestam atenção na medida em que esses recursos saem da retórica tradicional e estabelecem, per si, links com sua realidade num modal que se adéqua aos seus interesses.

A importância da discussão sobre a condição da criança no mundo contemporâneo está diretamente relacionada à discussão sobre "como aprender". Então, o ensino teria como uma de suas metas desenvolver a capacidade de formular perguntas, $o$ que, no sentido mais próprio do conceito, é o foco, a meta de um pensamento que se propõe filosófico, predisposto à discussão, "aberto ao mundo". Daí a importância de pensar a reflexão filosófica desde a mais tenra infância.

\section{As crianças e a Filosofia}

No Brasil é sempre discutível e incerta a posição sobre o ensino de Filosofia no que diz respeito à política pública - só há alguns anos o ensino de Filosofia voltou a fazer parte da matriz curricular do ensino médio no Brasil; o que dizer sobre o ensino de filosofia para crianças?

Do ponto de vista da discussão do ensino de filosofia para crianças esbarramos em, pelo menos, dois grandes preconceitos:

a) A premissa de que as crianças são incapazes de refletir e abstrair;

b) A premissa de que o pensamento que "realmente importa" é, exclusivamente, aquele proposto pela Escola. 
Para uma lógica neoliberal predominante no contexto contemporâneo, que se apropria, se nutre, valoriza e constrói uma racionalidade instrumental, a Filosofia é algo dispensável e sua inclusão no currículo "deve ser combatida". Os detratores de plantão do ensino de Filosofia preconizam que ela não é para "qualquer um". Essa postura perpassa a história da Filosofia. Platão escreveu no frontispício de sua ACADEMIA: "não entre aqui quem não souber Geometria” (DURANT, 1999, p. 67). Para ele é somente após o domínio da aritmética, da geometria, plana e estereométrica, e da astronomia que o estudante estará apto a iniciar os estudos da dialética que o levará para a vida teórica, própria da Filosofia. Na Idade Média, a expressão magister dixit prescinde de comentários. Em Kant (2005), o esclarecimento é a passagem de uma "menoridade" para uma "maioridade", concepção esta que está fundada e reforça preconceitos e estereótipos quanto a uma suposta "incompetência" para o pensar. Esses são alguns exemplos que ainda hoje fundamentam posturas educacionais, pressupondo a dependência e capacidade de raciocínio e predisposição ao estudo em um sentido sui generis: a Filosofia, para alguns professores, seria uma "pérola jogada aos porcos", parodiando o ensinamento bíblico de forma enviesada.

Opondo-se a essa perspectiva reducionista quanto à potencialidade e predisposição universal ao pensamento filosófico, vale destacar, dentre outros, as interessantes observações de Kohan (2009). Segundo esse autor, a Filosofia é uma aposta na educação das crianças, sobretudo uma aposta na infância, na sua força, na liberdade e na alegria. Para Gaarden (1995), o que para o adulto parece banal, é misterioso para a criança, pois ela tem o poder de encantar-se com a realidade, posto que existam coisas que julgamos impossíveis que não as espantariam. Não valorizar essa postura e as perguntas delas decorrentes, desencorajá-las, significa destruir o dubium admirationis (a dúvida da admiração) de que tratava Aristóteles (BORNHEIN, 1983), requisito fundamental para o pensamento filosófico.

Portanto, a Filosofia não é um saber, mas uma relação afetuosa, de amor, philo, com o saber. Como bem o observa Kohan (2009), não se pode transmitir Filosofia, nem ensinar, do mesmo modo que não se pode educar. Isso põe grandes problemas para as instituições escolares que estão habituadas a ensinar "conteúdos". Predispor e motivar o pensamento filosófico nas crianças não é ter que fazer que as crianças aprendam um conteúdo, sobretudo o que se encontra nos livros dos filósofos e dos manuais de filosofia. A Filosofia não tem pretensões de ensinar a pensar "corretamente" ou "ensinar a ser ético" ou qualquer outra coisa do gênero. Resume-se, tão somente, o que é muito, a um espaço aberto à discussão. É nesse sentido que se pode dizer que a filosofia não se ensina, mas se aprende. "[...] não é um modo de saber, nem um modo de pensar [...] Isso significa que não pode ser ensinada na base da lógica da técnica e dos instrumentos." (KOHAN, 2009, p. 62).

Na contramão dessas ponderações, ocorrem situações altamente questionáveis dentro do processo educacional, como, por exemplo, a existência de sistemas de avaliação que têm como um de seus instrumentos mais usuais a "prova". Esse instrumento gera e reafirma constantemente um absurdo "medo de errar" frente ao "correto", ou seja, aquilo que é exclusivamente "passado" pelo professor ao aluno, algo absolutamente assombroso. Saem desse tipo de "formação" alunos tímidos intelectual e eticamente, que não conseguem aceitar ou propor a crítica. Esses estudantes estão, definitivamente, excluídos do processo de construção do conhecimento. A destruição da capacidade de questionamento e da criatividade do aluno limita ou mesmo elimina sua liberdade de expressão. Uma formação normalizadora/disciplinar na perspectiva de como Foucault nos apresenta estes conceitos suspende a originalidade e a autonomia. Essa concepção crítica quanto às consequências e efeitos desses processos escolares perversos é compartilhada por vários filósofos. Jaspers (1998) escreve que as crianças até os sete anos são gênios, mas que a escola se encarrega de torná-los "normais" ou de "bobificar" (a expressão é do autor). Dewey (1959) criticava, há muitas décadas, as péssimas condições nas quais os estudantes chegam ao ensino superior. O que é constatável, com algum grau de generalização nas salas de aula, é que questionar e formular uma pergunta já não são mais atos mentais espontâneos e recorrentes nos alunos do final do ensino fundamental, ensino médio e ensino superior. 
Para superar essa problemática, uma alternativa é que o professor deixe, como esse ignorante que se dizia Sócrates, que a criança se encante com o mundo, com a realidade. Cabe ao educador, seja pai ou docente, não tolher ou privar a criança dessa possibilidade, principalmente mediante o uso acrítico e indevido dos recursos tecnológicos à disposição das crianças. Hoje são ditas loas sobre as maravilhas dos netbooks, smartphones e tablets; a interrogação que paira sobre quem quer fazer a educação pela Filosofia, ou educar sem mais, é a questão sobre a disposição e uso destas tecnologias. De acordo com Meirieu,

Há, no coração da 'pedagogia socrática' uma verdade que é evidente, 'a caixa preta' nos escapa. Podemos criar reflexos condicionados, aferrar-nos à dupla estímulo-resposta, fazer levantar, sentar, andar, correr, recitar, identificar, cortar, aplaudir nossos alunos, mas não podemos jamais saber com certeza o que se passa na caixa preta no momento de seu comportamento. (MEIRIEU, 1994, p. 36).

Mediante essa condição da infância no mundo contemporâneo, qual seria o telos da educação? Segundo muitos autores, díspares em suas concepções de mundo e educação, como Rousseau, Kant, Marx ou Adorno, pode-se afirmar de modo generalista que todos eles, a despeito de diversos fundamentos epistemológicos e propostas metodológicas divergentes e mesmo opostas entre eles, pensam a educação como emancipação, como autonomização do sujeito, como desenvolvimento da consciência crítica. Seria essa condição possível e desejável às crianças?

Bom, vale lembrar considerações de alguns filósofos a esse respeito. Segundo Montaigne (1987, p. 24), "Visto que é a filosofia que nos instrui a viver e que é nela que a infância, como todas as outras idades, tem sua lição, por que não comunica-la? Ensinam-no a viver quando a vida já passou. [...] É um grande erro tornar a filosofia inacessível às crianças".

A possibilidade de ensino de filosofia para crianças é defendida enfaticamente por Benjamin (1985, p. 236-237), quando afirma que "A criança exige dos adultos explicações claras e inteligíveis, mas não explicações infantis [...] A criança aceita perfeitamente as coisas sérias, mesmo as mais abstratas e pesadas, desde que sejam honestas e espontâneas".
Alguns fatos confirmam que as crianças estão predispostas ao pensamento filosófico. Vejamos dois exemplos. Eu, Moser, lembro-me, com saudades, como qualquer pai ou mãe se lembra de seus filhos, de quando minha filha tinha cinco anos. Viajávamos de Santa Maria para Passo Fundo, numa linda tarde. Então, a menina de cinco anos disse-me: "Olha, paizinho: o sol está se pondo no horizonte!!" Acompanhava-nos um professor amigo, e este perguntou à queima-roupa: "Mas, minha filha, o que é o horizonte?" E ela, muito séria, olha para ele como que estranhando a pergunta: "Ora, tio Percy, o horizonte é a casinha do sol."

Do mesmo modo, noutra ocasião, aprendeu a palavra pensar, não sei com quem. E de repente, chamei-a para algo. E a resposta veio (imitando o pai): "Espera um pouco, estou pensando." Imediatamente fiz-lhe a pergunta: "E o que é pensar, minha princesa?" Ao que ela respondeu: "Ora, pensar é falar baixinho para mim mesmo". Certamente, essa reflexão é filosófica.

$\mathrm{Eu}$, Daniel, tenho diversas vezes me surpreendido com as atitudes de minha filha Amelie, que está hoje com quatro anos. Ainda há alguns dias, ela me comunicou que nossa cachorra (ainda filhote) "não tem educação", sendo, na sua concepção, que educação é "não fazer bobeira".

Outro momento que exemplifica o pensamento filosófico ocorreu há quase um ano. Naquela época, tínhamos em casa uma gata e um casal de coelhos. Quando os coelhos começaram a procriar, a gata, fatidicamente, caçou e matou um dos filhotes dos coelhos. A ideia do que poderia acontecer depois da morte a partir da experiência do enterro do coelhinho gerou vários comentários metafísicos sobre a finitude da vida e a transcendência associada a uma forte dose emocional. Foi, certamente, uma experiência significativa em vários aspectos.

Desculpem-nos se lhes contamos exemplos de nossas experiências. Acreditamos que cada leitor também deve conhecer ou ter vivido situações como essas, observáveis no contato com qualquer criança.

As crianças são os verdadeiros poetas e filósofos porque criam o mundo com sua linguagem, até o momento em que são obrigadas a seguir o caminho e a linguagem - o currículo escolar - que lhes são impostos. Cedo demais são instadas a deixar a 
imaginação e a fantasia para se debaterem com a dura realidade. É o momento em que se processa o início da colonização das crianças, nas palavras de Mandel (1973). Aliás, todas essas afirmações podem ser cobertas pela monumental abertura do Emílio, quando Rousseau (1990) afirma que a criança, ao nascer das mãos do "Supremo Arquiteto", é perfeita, mas a sociedade a corrompe.

A condição do ser humano como filósofo não garante a perenidade de uma postura reflexiva sobre o mundo. É necessário um processo de construção dialógica para que essa predisposição do espírito materialize-se nas práticas cotidianas. Daí a importância da discussão sobre metodologias de ensino de Filosofia para crianças, terceira parte deste artigo.

\section{Filosofia para crianças: aproximações metodológicas}

No Brasil, talvez, a primeira experiência do ensino de Filosofia para crianças, trabalhada aos moldes das proposições de Lipman, data de 1985, em São Paulo, sendo expandida esta experiência para diversos outros estados como Santa Catarina e Paraná. Essa experiência está associada à fundação do Centro Brasileiro de Filosofia para Crianças?.

As experiências com o ensino de Filosofia propostas por Lipman levaram-no a produzir, em 1989, um texto intitulado Reforçar o Raciocínio e o Julgamento pela Filosofia, trabalhando neste artigo sua reprodução no livro Filosofia para Crianças, o Modelo de Matthew Lipman em Discussão, de 2008. Neste texto, entre outros elementos, ele pontua algumas pressuposições de sua metodologia de trabalho com filosofia para crianças, parafraseadas abaixo.

Para Lipman (2008), o ensino de filosofia para crianças deve considerar os seguintes aspectos: ser imparcial (quanto às diferentes concepções filosóficas) e representativo (Filosofia em seu conjunto); não dogmático; respeitar o cabedal linguístico das crianças considerando sua predisposição ao pensamento filosófico; considerar que os problemas filosóficos fazem parte do universo infantil como

\footnotetext{
7 Essa Fundação está hospedada no site $<$ http://www.philosletera.org br $>$.
}

os conceitos de justo, belo, vida; as crianças gostam de perguntas e, portanto, a concepção de privação da abstração pelas crianças é um erro, mas esta abstração deve ser moderada; as crianças refletem melhor quando têm modelos, mas o ideal é a deliberação coletiva, formando grupos de pesquisa; as crianças aprendem melhor com narrativas, pois apreendem as significações contextuais; a inteligência se expressa de várias formas, mas a linguagem oral é fundamental, além da escrita; é importante a realização de exercícios para o desenvolvimento de aptidões cognitivas e planos de discussão, para consolidar a conceitualização da realidade; os exercícios devem ser elaborados por especialistas e não pelo professor da disciplina (algo questionável); o raciocínio é uma técnica (pode ser ensinado) e o julgamento é uma arte (aprende-se por si), necessitando um ambiente estimulante para ambos.

A partir dos tópicos anteriores e das considerações de Lipman (2008) e outros pesquisadores que tratam do ensino de Filosofia para crianças, alguns aspectos merecem destaque.

Em primeiro lugar, é necessário observar que há um imenso abismo entre o saber do professor de filosofia e o modo de pensar das crianças. Esquecemos, quase todos nós, que fomos crianças. Em segundo lugar, ao aprender algo novo, desaprendemos algo: uma nova aprendizagem é um novo comportamento, aprende-se desaprendendo, esta é a lei. Há, portanto, muita distância entre a weltanschauung dos adultos e o modo de ver o mundo das crianças. Basta que vejamos os filmes, por exemplo, como História sem Fim, O Mistério do Cristal ou OJardim Secreto e comparemos nossas interpretações com as das crianças. Quais são os desenhos animados que as crianças apreciam, e quais apreciamos nós? As músicas? E assim por diante. Podemos empregar palavras também usadas pelas crianças, mas talvez apenas o ruído seja o mesmo: não se processa a verdadeira comunicação, que é uma comum + união, uma sintonia. Nessa linha de raciocínio, qual seria uma das origens da indiferença/apatia dos alunos em sala de aula?

Em segundo lugar, é importante considerar se seria mais importante pensar o método enquanto incentivo à pesquisa e reflexão do que o conteúdo propriamente dito. Resgata-se, aqui, duas experiências que poderiam ajudar a pensar essa problemá- 
tica. Primeiro, a experiência Jacotot. No início do século XIX, em razão de certas condições históricas específicas, Jacotot lançou o desafio a seus alunos para aprenderem uma segunda língua por meio da apresentação de um texto bilíngue, sem intervenção do professor, discutindo com isso o conceito de emancipação do aluno, como bem trabalhado por Rancière (2002). Segundo, a experiência proposta por Postman e Weingartner (1973) sugerindo que o professor de matemática lecione inglês ou geografia. E que os professores de geografia, história, línguas ensinem disciplinas totalmente diferentes daquelas a que estão acostumados a ensinar. Se não o conseguem, segundo esses autores, é porque não sabem se comunicar.

Em terceiro lugar, conceber o ensino de filosofia para crianças não significa, necessariamente, criar uma nova disciplina no currículo da educação infantil. Implica, tão somente, que os educadores ponham à disposição dos alunos metodologias de aprendizagem eficazes. Com essas metodologias, porão à disposição das crianças materiais e utensílios necessários (as informações básicas) e lhes possibilitarão efetuar as operações mentais indispensáveis: deduzir, antecipar, analisar, efetuar sínteses e outras. É uma das funções da escola providenciar para que todos os alunos adquiram essas competências.

Em quarto lugar, é necessária uma postura dialógica. Essa postura nega um ensino norteado pela escola tradicional, ou seja, pelo uso indiscriminado de mecanismos de respostas fechadas (ainda que de "múltiplas escolhas"), "truques/pegadinhas" na formulação das questões, o resumo de conteúdos a "macetes". Essas e outras práticas assemelhadas transformam o processo educacional numa verdadeira tortura, já que o conhecimento apresentado e cobrado é puro non sense para os estudantes. Quando incentivado, o aluno pesquisa fora da sala: a limitação do tempo e do espaço na escola para discussão dos temas torna-se a motivação para seu prolongamento em outros momentos, fazendo a passagem da condição de a-luno (sem luz) para estudante, pensador. É na infância que a reflexão produzida coletivamente produz as condições necessárias para uma concepção democrática de sociedade. É necessária a (re)produção de uma cultura da "pergunta", na constituição de "comunidades de investigação". Não basta romper com a opinião: é preciso problematizá-la. Essa comunidade de investigação, como proposta por Wenger (1998, 2002) e propiciada pela TICs, corresponde a um conjunto de procedimentos e atitudes que garantem uma discussão coletiva sobre temas diversos, numa perspectiva filosófica.

$\mathrm{Na}$ ótica do pensamento moderno, quando Descartes escreve "Je", este representa o sujeito universal, o sujeito racional que fala tendo ideias claras e evidentes e que devem ser aceitas por todos. Repensar tal concepção é fundamental para compreender as dinâmicas sociais contemporâneas, em que o professor se apresenta como facilitador, alguém que coopera para a aceitação da correção lógica ou problematização da diversidade dos argumentos pelos colegas ou pelo professor. $\mathrm{O}$ aprender a pensar está relacionado à aplicação de atividades a partir dos interesses manifestados pelas crianças - reflexão provocada -, análise da experiência e da atividade.

Enfim, é importante lembrar que todo conhecimento tem seu caráter social, posto que é construído por homens em sociedade a partir de seus problemas historicamente construídos. O que é importante na existência humana é expressar ideias e sentimentos - a violência, seja no seio familiar, seja nas guerras internacionais, está associada a uma impossibilidade de compreensão e conversação no que se refere a conteúdo e sentimentos. Essa condição social demanda a necessidade de produção de um "conhecimento prudente para uma vida decente", como nos ensina Santos, B. S. (2004). A reflexão filosófica pode, em muito, ajudar nesse processo.

\section{CONSIDERAÇÕES FINAIS}

Como (re)pensar a prática de formação das crianças para o exercício do pensamento filosófico? Como essas experiências de significação e ressignificação da realidade pelo pensamento filosófico podem ser resgatadas no estudante em processo de formação?

Aprender por si mesmo é uma predisposição da condição humana e, mesmo, uma necessidade. Toda existência é tomada de posição e julgamento. Nesse sentido, é fundamental pensar o processo 
educativo numa perspectiva filosófica, pela construção de comunidades de pesquisa.

É fundamental perceber o processo educacional sob a ótica do prazer pela reflexão. Estabelecer questionamentos que dizem respeito ao cotidiano dos alunos, deixando de lado temas bizantinos e abstratos que nada significam para as crianças e jovens pós-modernos. Ensinar a aprender a viver.

Despertar o interesse filosófico é fazer perguntas sobre questões que os estudantes queiram discutir. Se o aluno não é chamado para a responsabilidade do processo ele, definitivamente, é excluído dele. A elaboração de uma agenda coletiva de discussão, realizada entre pares, permite pensar o processo de forma circular-colaborativa. Esse movimento contextualiza sentidos, desperta e valoriza a criatividade.

Entendemos que o objetivo do ensino de filosofia não é colocar o estudante, de qualquer idade, em contato com algum filósofo e suas teses (elemento acessório), mas, fundamentalmente, prepará-lo para enfrentar os desafios do século XXI estimulando competências relacionadas à reflexão e ao diálogo, fundamentos de um pensamento crítico, que tenham por finalidade a busca por soluções dos problemas cotidianos a partir de uma postura democrática.

\section{REFERÊNCIAS}

ALMEIDA, D. Empresas pagam até R\$ 1,8 mi para estar no final de Avenida Brasil. Época Negócios, Rio de Janeiro, 19 out. 2012. Disponível em: <http://epocanegocios.globo.com/Informacao/Resultados/noticia/2012/10/ final-de-avenida-brasil-tem-propaganda-r-500-mil-e-merchandising-de-ate-r-18-mi.html >. Acesso em: 04 dez. 2012.

ARIÈS, P. História social da criança e da família. Rio de Janeiro: LTC, 1978.

BAUMAN, Z. O mal-estar da pós-modernidade. Rio de Janeiro: Zahar, 1998. Ética da pós-modernidade. São Paulo: Paulus, 1999. Amor líquido. Rio de Janeiro: Zahar, 2003.

Identidade. Rio de Janeiro: Zahar, 2005.

BAUERLEIN, M. The dumbest generation: how the digital age stupefies young americans and jeopardizes our future - or don't trust anyone under 30. New York: Tarcher, 2008.

BENJAMIN, W. Obras escolhidas I: magia e técnica, arte e política. São Paulo: Brasiliense, 1985.

BORNHEIN, G. Introdução ao pensar. São Paulo: Pallas, 1983.

BRASIL. Lei n. 8.069, 13 de julho de 1990. Dispõe sobre o Estatuto da Criança e do Adolescente e dá outras providências. Diário Oficial [da] República Federativa do Brasil. Brasília, DF, 16 jul. 1990. Disponível em: <www. planalto.gov.br/ccivil_03/leis/18069.htm>. Acesso em: 14 out. 2012.

CASTELLS, M. A galáxia da Internet: reflexões sobre a Internet, os negócios e a sociedade. Rio de Janeiro: Zahar, 2003.

CHAUÍ, M. Convite à Filosofia. São Paulo: Ática, 2004.

DAWKINS, R. Deus, um delírio. Tradução de Fernanda Ravagnani. São Paulo: Companhia das Letras, 2007.

DEWEY, J. Democracia e Educação. 3. ed. Tradução de Godofredo Rangel e Anísio Teixeira. São Paulo: Nacional, 1959.

DURANT, W. A filosofia de Platão. Rio de Janeiro: Tecnoprint, 1999.

FANTIN, M.; RIVOLETTA, P. C. Crianças na era diginal: desafios da comunicação e da educação. REU, Sorocaba, SP, v. 36, n. 1, p. 89-104, 2010.

GAARDEN, J. O mundo de Sofia. 4. ed. São Paulo: Cia. das Letras, 1995. 
HARVEY, D. A condição pós-moderna. São Paulo: Loyola, 1993.

IANNI, O. A era do globalismo. Rio de Janeiro: Civilização Brasileira, 1996.

JASPERS, K. Introdução ao pensamento filosófico. São Paulo: Cultrix, 1998.

JONAS, H. O princípio da responsabilidade: ensaio de uma ética para uma civilização tecnológica. Rio de Janeiro: PUC-Rio, 2006.

KANT, I. Resposta à pergunta: Que é esclarecimento? Textos Seletos. Tradução Floriano de Sousa Fernandes. 3. ed. Petrópolis, RJ: Vozes, 2005.

KOHAN, W. O. A educação de crianças pelo olhar da filosofia. Educação \& Psicologia, São Paulo, n. 2, p. 6-17, maio 2009.

LELEUX, C. Filosofia para crianças. Porto Alegre: Artmed, 2008.

LIPMAN, M. A filosofia vai à escola. 2. ed. São Paulo: Summus, 1990.

Thinking in education. 2. ed. United Kingdom: Cambridge University Press, 2008.

MANDEL, G. Para descolonizar a criança. Lisboa: Edições D. Quixote, 1973.

MEIRIEU, P. Apprendre... oui, mais comment. 13. ed. Paris: TSF, 1994.

MONTAIGNE, M. Ensaios, 2. ed. Brasília, DF: UnB/Hucitec, 1987.

PARMÊNIDES. Os pensadores. São Paulo: Abril Cultural, 1973.

PLATÃO. República. Bauru, SP: Edipro, 1994.

POSTMAN, N. O desaparecimento da infância. Rio de Janeiro: Graphia, 1999.

; WEINGARTNER, C. Contestação: nova formula de ensino. 3. ed. Rio de Janeiro: IBRASA, 1973.

PRENSKY, M. Digital natives, digital immigrants. MCB University Press, 2001. Disponível em: <http://www. marcprensky.com/writing/Prensky\%20\%20Digital\%20Natives,\%20Digital\%20Immigrants\%20\%20Part1.pdf>. Acesso em: 26 set. 2010.

Não me atrapalhe, mãe - eu estou aprendendo! São Paulo: Phorte, 2010.

RANCIÈRE, J. O mestre ignorante. Belo Horizonte: Autêntica, 2002.

ROTTERDAM, E. De pueris. A civilidade pueril. São Paulo: Escala, 2008. (Coleção Grandes Obras do Pensamento Universal).

ROUSSEAU, J-J. Emilio. Martins: Publicações Europa-América, 1990.

SADER, E. Os porquês da desordem mundial - mestres explicam a globalização. Rio de Janeiro: Record, 2004.

SALGADO, R. G.; PEREIRA, R. M. R.; JOBIM E SOUZA, S. Pela tela, pela janela: questões teóricas e práticas sobre infância e televisão. Caderno CEDES, Campinas, v. 25, n. 65, p. 9-24, jan./abr. 2005. Disponível em: $<$ http:// www.scielo.br/scielo.php?script=sci_arttext\&pid=S0101-32622005000100002\&lng=pt\&nrm=iso $>$. Acesso em: 14 nov. 2012.

SANTAELla, L. Cultura e artes do pós-humano. São Paulo: Paulus, 2003.

SANTOS, B. S. (Org.). Conhecimento prudente para uma vida decente: um discurso sobre as ciências revisitado. São Paulo: Cortez, 2004.

SANTOS, M. Por uma outra globalização: do pensamento único à consciência universal. Rio de Janeiro: Record, 2000.

TAPSCOTT, D. Growingupdigital: therise of the netgeneration. New York: McGraw-Hill, 1997. 
WENGER, E. Communities of practice - learning, meaning and identity. Cambridge: Cambridge University Press, 1998.

; MCDERMOTT, R.; SNYDER, W. Cultivating communities of practice. Boston: Harvard Business School Press, 2002.

Recebido em 08.12.2012

Aprovado em 05.02.2013 